\title{
Effect of Health Education on Healthcare-Seeking Behavior of Migrant Workers in China
}

\author{
Xuefeng $\mathrm{Li}^{1}{ }^{1} * \mathbb{D}$, Han Yang ${ }^{1}\left(\mathbb{D}\right.$, Hui Wang ${ }^{2}$ and Xujun Liu ${ }^{3}$ \\ 1 Western China Economic Research Center, Southwestern University of Finance and Economics, \\ Chengdu 611130, China; fzyanghan@126.com \\ 2 School of Accounting, Southwestern University of Finance and Economics, Chengdu 611130, China; \\ wanghui@swufe.edu.cn \\ 3 School of Finance, Southwestern University of Finance and Economics, Chengdu 611130, China; \\ lxujun@smail.swufe.edu.cn \\ * Correspondence: lixuefeng@swufe.edu.cn; Tel.: +86-186-0284-9976
}

Received: 19 February 2020; Accepted: 28 March 2020; Published: 30 March 2020

\begin{abstract}
Health education is considered to be an effective way to improve the healthcare-seeking behavior of migrant workers. This study examined the impact of health education on healthcare-seeking behavior of migrant workers in China and explored the differences in different health education methods. This paper used the 2017 China Migrants Dynamic Survey (CMDS) to analyze the relationship between health education and healthcare-seeking behavior. Our results indicated that health education could significantly improve the healthcare-seeking behavior of migrant workers, but there was still ample space for improvement. From the perspective of different health education methods, lectures, public consultation, and online education were positively correlated to healthcare-seeking behavior, while publicity materials and bulletin boards were not. Although the effects of publicity materials and bulletins were limited, these two health education methods were still the most widely used. Our results emphasized the necessity of increasing investment in lectures, public consultation, online education, and other similar health education methods. This change in health education methods can play an effective role in the spread of health education to improve the healthcare-seeking behavior of migrant workers.
\end{abstract}

Keywords: health education; healthcare-seeking behavior; migrant worker; China

\section{Introduction}

The term 'migrant workers' refers to the labor force groups who work as temporary residents in non-registered locations without changing their household registration [1]. In 2018, China's migrant workers reached 288.36 million, accounting for $20.7 \%$ of the total population [2]. However, due to the restrictions of the household registration system in China, plenty of migrant workers can only live in working cities temporarily, resulting in their unequal treatment by public services [3-5]. Among them, the inequality of health services is particularly severe. For example, migration reduces the probability of using health records [6]; most of the migrant workers do not even establish health records in their working city. In order to reduce the health risks caused by inadequate health services and ensure social equity, the Chinese government has formulated a series of policies to improve the availability of health services for migrant workers.

In improving the availability of health services, it is also essential to guide migrant workers to develop scientific healthcare-seeking behavior. To a considerable extent, healthcare-seeking behavior remarkably affects health-related quality of life of migrant workers [7]. Based on an extensive sample survey conducted by the Ministry of Health of China, the utilization of public health services by 
migrant workers was generally low [8]. Some case studies have also confirmed this conclusion $[9,10]$. Therefore, it is necessary to analyze the factors that affect the healthcare-seeking behavior of migrant workers. Understanding these factors is essential for health-related measures concerning migrant workers [11]. Among these factors, health literacy is of wide concern. Health literacy refers to the factors that affect a person's ability to access, understand, and use information about health and health services [12]. Current research proves that health literacy is positively related to healthcare-seeking behavior [13-16].

People with insufficient health literacy may delay seeking health services due to not knowing preventive measures or the symptoms of the disease [17]. Compared with residents, the health literacy of migrant workers is lower [18]. Especially during the outbreak of large-scale infectious diseases, due to lack of health literacy, some migrant workers do not seek medical treatment or even choose to cross-regional flow, which becomes the carrier of virus transmission. Taking severe acute respiratory syndrome (SARS) as an example, due to their mobility and their lack of health awareness, migrant workers brought difficulties to the government in controlling infectious diseases [19]. COVID-19 broke out during the Chinese Lunar New Year. Most of the migrant workers had returned to their hometown, and rural areas were not the core areas of the epidemic, so the health of migrant workers was less affected. But the current situation does not mean that migrant workers will not be affected or affect others in future epidemics. Therefore, it is of significance to improve the health literacy of migrant workers to ensure that they can actively seek health services after their illness. An improvement in educational literacy not only protects the health service rights of migrant workers but also prevents and controls the spread of diseases.

At present, strengthening health literacy through health education has become the universal suggestion of most scholars to optimize people's healthcare-seeking behavior [20-22]. Research shows that integrating health knowledge into education is a fair and effective way to promote the health of children and adolescents [23]. A study of Indian women found that, after receiving health education, women can significantly improve the utilization of maternal health care [24]. Although several scholars have studied the relationships between health education and healthcare-seeking behavior, few had studied them in migrant workers. There are various methods to disseminate health education. Different health education methods have different knowledge dissemination mechanisms, hence the difference in the corresponding educational effects. The existing research discussed the approaches to health education from various aspects, such as peer group health education, telephone health education, Internet-based training, etc. $[25,26]$. At present, the most effective method of health education for migrant workers still lacks research.

The purpose of this study is to analyze the relationship between health education and healthcare-seeking behavior of migrant workers in China. We used a representative national survey to explore the following questions: (1) the specific characteristics of healthcare-seeking behavior of migrant workers; (2) whether health education changes the healthcare-seeking behavior of migrant workers; (3) whether existing health education methods show differences in changing healthcare-seeking behavior of migrant workers. Through discussion of the above problems, we put forward some suggestions for improving health education methods.

\section{Chinese Health Education Background and Literature}

Since the 1980s, provincial health education institutions have been set up in various parts of China to undertake the dissemination of health knowledge in the region. Large and medium-sized cities and even some counties have established health-education institutions. Various medical and health institutions at all levels began to establish corresponding health education departments. The communication network of China's health education system has been gradually developed and improved [27], which provides the primary carrier for health education. To some extent, this means the germination of China's health education awareness. 
In the 1990s, the Chinese government gradually attached importance to the health education of migrant workers. In 1994, China launched the National Health Education Project for 900 Million Farmers (NAHEF), targeting educational objects including migrant workers, marking the official start of health education at the grassroots level in China. With the promotion of NAHEF, health education methods have been continuously improved. The health education of migrant workers has been determined and organized by communities and villages. Based on local culture and customs, information on health education is widely disseminated through mass media. This method combines mass media and interpersonal communication to improve farmers' health awareness.

In April 2003, NAHEF was renamed as the National Health Promotion Project for Hundreds of Millions of Chinese Farmers (NAHPF). The goal of the project changed from process-oriented health education activities to result-oriented health promotion, marking that the health education of migrant workers has entered a new stage. The Chinese government has further standardized the service forms and requirements of rural health education activities. However, due to the characteristics of sizeable regional mobility and low educational level, the health education effect on migrant workers is not ideal $[28,29]$. At present, based on the effective use of the existing health education communication network, there is little research on the best method of health education. Therefore, this paper discusses this topic.

\section{Materials and Methods}

\subsection{Data Source}

The data used in this article is derived from the 2017 CMDS. CMDS is an annual, large-scale national survey of the migrant population conducted by the National Health Commission of China. The respondents of this survey are migrants aged 15 and above who are not registered in the sample district (county, city) and have lived in the sample location for more than one month. The sample locations were selected from the areas with a concentrated migrant population in 31 provinces (districts, cities) and Xinjiang Production and Construction Corps, with 32 provincial units in total.

The survey was divided into three sampling stages by a multi-stage probability method proportional to size. The first stage was to select townships (towns and streets) in proportion among 32 provincial units. In the second stage, village committees were selected based on the size of the chosen townships (towns and streets). The third stage was to investigate the qualified individuals from the chosen village committees. The survey comprehensively collected detailed information about the migrant population, including necessary information about public health services, social security, health status, employment, etc. Using diarrhea, fever, skin rash, and common cold as tracer diseases, we selected migrant workers who had suffered from one of these four diseases in the past year as samples. After eliminating some samples with missing data, we obtained 40,951 observations in the final sample.

\subsection{Measures}

\subsubsection{Dependent Variables}

Healthcare-seeking behavior is a kind of social behavior. People adopt this behavior to confirm the existence of disease and alleviate the pain of disease [30]. We divided the health-seeking behavior into several parts, including attitude to treatment, choice of treatment method, choice of medical institution, medical expenses, etc. At present, China still faces the problem that not enough migrant workers choose to seek healthcare after illness. It is necessary to guide migrant workers to encourage scientific healthcare-seeking behavior. The primary task is forming the right treatment attitude so that they can seek healthcare in time after their illness. Therefore, we chose to seek healthcare after illness as a measure of migrant workers' healthcare-seeking behavior. 
Using diarrhea, fever, skin rash, and common cold as tracer diseases, we constructed the corresponding dependent variables. Specifically, diarrhea indicates whether to seek healthcare when the frequency of diarrhea is more than or equal to three times per day. Fever indicates whether to seek healthcare when the body temperature is higher than $38^{\circ} \mathrm{C}$. Skin rash indicates whether to seek healthcare when there is abnormal color, bulge, or blister on the skin surface. Common cold indicates whether to seek healthcare when a cold occurs. All of the dependent variables were assigned to $0-1$ ( $1=$ seek healthcare after the illness, $0=$ otherwise $)$.

\subsubsection{Independent Variables}

We selected whether migrant workers had received health education $(1=$ yes, $0=$ no) and five methods of receiving health education as independent variables. The methods of receiving health education are lectures (whether to receive health education through health knowledge lectures, $1=$ yes, $0=$ no), publicity material (whether to receive health education through publicity materials, e.g., newspapers, film and television, $1=$ yes, $0=$ no), bulletin board (whether to receive health education through bulletin board/electronic display screen, $1=$ yes, $0=$ no), public consultation (whether to receive health education through public health consultation, $1=$ yes, $0=$ no), and online education (whether to receive health education through short message service/WeChat/website, $1=$ yes, $0=$ no).

\subsubsection{Control Variables}

In order to control other variables that may affect the research results, we used detailed information about the characteristics of each migrant worker as control variables. We controlled gender $(1=$ male, $0=$ female), age, education level, health status, household income, employment status, service project publicity, health record, social security card, and cooperative medical insurance.

More precisely, education level reflects the highest education level of the migrant worker. Responses were given on a 7-point rating scale, ranging from 1-7: 1 (have not attended school), 2 (primary school), 3 (junior high school), 4 (technical school or senior high school), 5 (junior college), 6 (bachelor degree), 7 (master's degree and above). Health status represents the health level of the migrant worker. Responses were given on a 4-point rating scale: 1 (I don't have the ability to take care of myself), 2 (unhealthy, but have the ability to take care of myself), 3 (relatively healthy), 4 (healthy). Household income is the logarithm of the average monthly income of the household in the past year. Employment status reflects whether the migrant worker has had paid jobs in the past week ( $1=$ yes, $0=$ no). Health service publicity reflects whether the migrant worker knows the national project concerning essential public health services $(1=$ yes, $0=$ no). Health record depends on whether the migrant worker has established a resident health record $(1=$ yes, $0=$ no). Social security card reflects whether the migrant worker has applied for personal social security card $(1=$ yes, $0=$ no). Basic medical insurance indicates whether the migrant worker participated in basic medical insurance (1 = yes, $0=$ no).

\subsection{Estimation Method}

The dependent variables in this paper were 0-1 indicator variables. Considering that the Probit model could deal with heteroscedasticity and non-normality better than the linear probability model [31], we used the Probit model to estimate the probability of healthcare-seeking behavior when migrant workers were ill. The regression model was as follows:

$$
Y=\alpha+\varepsilon+\sum_{i} \beta_{i} X_{i}+\sum_{j} \gamma_{j} M_{j}
$$

In this model, $\mathrm{Y}$ represented the dependent variable to measure healthcare-seeking behavior, $\mathrm{X}_{\mathrm{i}}$ denoted the independent variables, including different types of health education, $\mathrm{M}_{\mathrm{j}}$ represented the control variables, and $\varepsilon$ represented the error term. The coefficients $\beta$ and $\gamma$ represented the partial 
effects of independent variables and control variables on prediction probability, respectively. We used STATA 13.1 ((Stata Corporation, College Station, Texas, TX, USA) for model regressions.

\section{Results}

\subsection{Descriptive Analysis}

The descriptive statistics of each variable are shown in Table 1. There are 40,951 migrant workers in the sample. Among them, the number of sampled migrants who had diarrhea, fever, skin rash, or common cold was $23,506,20,266,6815$, and 35,119 , respectively, with $29.3 \%, 51.6 \%, 55.2 \%$, and $39.4 \%$ choosing to seek healthcare. In general, $67.6 \%$ of the migrants received health education. Among them, the proportion of migrant workers receiving health education through publicity materials and bulletin boards was higher, with $83.8 \%$ and $72.7 \%$, respectively. However, only a few migrant workers received health education through lectures, public health consultation, and online education, accounting for $37.9 \%, 41.6 \%$, and $38.6 \%$, respectively.

Table 1. Descriptive statistics of variables.

\begin{tabular}{cccc}
\hline Variable & Mean & Standard Deviation & Observation \\
\hline Diarrhea & 0.293 & 0.455 & 23,506 \\
Fever & 0.516 & 0.500 & 20,266 \\
Skin rash & 0.552 & 0.497 & 6815 \\
Common cold & 0.394 & 0.489 & 35,119 \\
Health education & 0.676 & 0.468 & 40,951 \\
Lecture & 0.379 & 0.485 & 27,683 \\
Publicity material & 0.838 & 0.369 & 27,683 \\
Bulletin board & 0.727 & 0.446 & 27,683 \\
Public consultation & 0.416 & 0.493 & 27,683 \\
Online education & 0.386 & 0.487 & 27,683 \\
Gender & 0.512 & 0.500 & 40,951 \\
Age & 35.81 & 11.26 & 40,951 \\
Education level & 3.492 & 1.218 & 40,951 \\
Health status & 3.671 & 0.579 & 40,951 \\
Household Income & 8.666 & 0.820 & 40,951 \\
Employment status & 0.811 & 0.391 & 40,951 \\
Health service publicity & 0.578 & 0.494 & 40,951 \\
Health record & 0.257 & 0.437 & 40,951 \\
Social security card & 0.506 & 0.500 & 40,951 \\
Basic medical insurance & 0.732 & 0.443 & 40,951 \\
\hline
\end{tabular}

In terms of characteristics of the sampled migrant workers, the proportion of males and females was relatively balanced ( $51.2 \%$ were male). The average age was 35.8 years, the average educational background was higher than junior high school, and health scored relatively healthy on average, indicating that the sampled migrant workers were a middle-aged and strong labor force. $81.1 \%$ of the sampled migrants had paid jobs in the past week, and the average monthly income of the household in the past year was 5802 yuan (According to the survey of National Bureau of Statistics of China in 2017, the average number of people in a household was 3 (including urban and rural households), and the per capita annual disposable income of urban residents was 36,396 yuan. That is to say, the average monthly income of urban households was 9099 yuan, far higher than that of migrant workers.). $73.2 \%$ of migrants had basic medical insurance, indicating that the popularization of basic medical insurance was excellent. Besides, $57.8 \%$ of the migrant workers had heard about the national basic public health service project, $50.6 \%$ had a personal social security card, and only $25.7 \%$ had created residents' health records, showing that the development of health services in China still needs to be improved. 
Table 2 shows the reasons whey migrants did not choose healthcare-seeking behavior. Among the four kinds of diseases, the reasons for not seeking health care were similar. More than $50 \%$ of the migrant workers in the sample thought they had knowledge of because they had heard of it before. This answer was the primary reason why they chose not to seek healthcare after being ill. The second reason was that they were too busy to seek healthcare, accounting for $22.8-32.5 \%$ among the four diseases. The proportions of migrant workers who reported "I think my body can be self-healing," "I am short of money to seek healthcare," or "It is too much trouble to go to the hospital" were all less than $10 \%$.

Table 2. Reasons for not seeking healthcare.

\begin{tabular}{ccccc}
\hline Reasons & Diarrhea & Fever & Skin Rash & Common Cold \\
\hline I had it before, I think I have treatment experience. & 0.553 & 0.520 & 0.500 & 0.533 \\
I think my body can be self-healing. & 0.066 & 0.064 & 0.091 & 0.072 \\
I am too busy to seek healthcare. & 0.325 & 0.256 & 0.228 & 0.275 \\
I am short of money to seek healthcare. & 0.066 & 0.075 & 0.089 & 0.068 \\
It is too much trouble to go to the hospital. & 0.054 & 0.067 & 0.087 & 0.055 \\
\hline
\end{tabular}

Note: This question is multiple-choice, and the response "other causes" is not included in the table.

In Table 3, we analyzed the differences in healthcare-seeking behavior between migrant workers who had received relevant health education and those who had not. It was observed that people with health education were more likely to seek healthcare. Taking diarrhea as an example, $30.9 \%$ of the migrant workers who had received health education chose to seek healthcare after the illness, while only $26.2 \%$ of the migrant workers without health education did. Furthermore, among all the methods of health education, a higher proportion of those who had received health education sought healthcare than those who had not. This phenomenon was similar among the four groups. We also took diarrhea as an example. The proportion of migrant workers who went to seek healthcare after attending lectures was $34.3 \%$, while the proportion who did not attend was $28.9 \%$. By the univariate $t$-test, among all kinds of disease and all methods of receiving health education, there were significant differences between the migrants who had received health education and those who had not $(p<0.01)$. In the next section, we use rigorous econometric regression analysis to analyze the relationship between health education and healthcare-seeking behavior.

Table 3. Descriptive statistics and healthcare-seeking behavior data.

\begin{tabular}{cccccc}
\hline Variable & & Diarrhea & Fever & Skin Rash & Common Cold \\
\hline \multirow{3}{*}{ Health education } & Yes & 0.309 & 0.532 & 0.572 & 0.412 \\
& No & 0.262 & 0.48 & 0.509 & 0.356 \\
& Difference & $0.047^{*}$ & $0.053^{*}$ & $0.062^{*}$ & $0.055^{*}$ \\
& Yes & 0.343 & 0.556 & 0.621 & 0.439 \\
Knowledge lecture & No & 0.289 & 0.517 & 0.542 & 0.395 \\
& Difference & $0.054^{*}$ & $0.038^{*}$ & $0.079 *$ & $0.045^{*}$ \\
& Yes & 0.313 & 0.537 & 0.583 & 0.415 \\
Publicity material & No & 0.288 & 0.51 & 0.519 & 0.392 \\
& Difference & 0.026 & 0.027 & $0.064^{*}$ & $0.023^{*}$ \\
Bulletin board & Yes & 0.318 & 0.544 & 0.58 & 0.421 \\
& No & 0.286 & 0.501 & 0.549 & 0.386 \\
Public consultation & Difference & $0.032 *$ & $0.043 *$ & 0.031 & $0.035^{*}$ \\
& Yes & 0.344 & 0.567 & 0.623 & 0.447 \\
& No & 0.285 & 0.507 & 0.536 & 0.386 \\
Online education & Difference & $0.059 *$ & $0.061 *$ & $0.087^{*}$ & $0.061^{*}$ \\
& Yes & 0.342 & 0.566 & 0.621 & 0.445 \\
& No & 0.289 & 0.511 & 0.541 & 0.39 \\
& Difference & $0.052 *$ & $0.055^{*}$ & $0.081^{*}$ & $0.055^{*}$
\end{tabular}

Note: * denotes statistically significant difference at the $1 \%$ significance level. "Yes" means having received the relevant health education, "No" otherwise. 


\subsection{Regression Results}

Table 4 showed the main results of multivariate analysis. The dependent variable was whether a migrant worker choose to seek healthcare after a tracer disease. For each explanatory variable, we reported the estimated marginal effect. In the regression, province dummies were included to control for potential province fixed effects. The results showed that receiving health education was positively associated with healthcare-seeking behavior. In detail, after receiving health education, the probability of migrant workers seeking healthcare for diarrhea increased by $3.2 \%$. The effect of health education on migrant workers with fever, skin rash, and common cold is similar, at $1.9 \%, 3.9 \%$, and $2.7 \%$, respectively.

Table 4. Effect of health education on healthcare-seeking behavior (Probit).

\begin{tabular}{|c|c|c|c|c|}
\hline Variable & Diarrhea & Fever & Skin Rash & Common Cold \\
\hline \multirow{2}{*}{ Health education } & $0.032^{* * *}$ & $0.019^{* *}$ & $0.039 * * *$ & $0.027 * * *$ \\
\hline & $(0.007)$ & $(0.008)$ & $(0.014)$ & $(0.014)$ \\
\hline \multirow{2}{*}{ Gender } & $-0.025^{* * *}$ & -0.012 & $-0.036^{* * *}$ & $-0.023^{* * *}$ \\
\hline & $(0.006)$ & $(0.007)$ & $(0.012)$ & $(0.012)$ \\
\hline \multirow{2}{*}{ Age } & $0.001 *$ & $-0.002 * * *$ & $-0.001 * *$ & $-0.001^{* * *}$ \\
\hline & $(<0.001)$ & $(<0.001)$ & $(0.001)$ & $(0.001)$ \\
\hline \multirow{2}{*}{ Education level } & $-0.009^{* * *}$ & 0.003 & $0.015^{* *}$ & $-0.008^{* * *}$ \\
\hline & $(0.003)$ & $(0.004)$ & $(0.006)$ & $(0.006)$ \\
\hline \multirow{2}{*}{ Health status } & $-0.026^{* * *}$ & $-0.031^{* * *}$ & -0.007 & $-0.016^{* * *}$ \\
\hline & $(0.006)$ & $(0.007)$ & $(0.011)$ & $(0.011)$ \\
\hline \multirow{2}{*}{ Household Income } & -0.001 & 0.006 & 0.009 & 0.005 \\
\hline & $(0.004)$ & $(0.005)$ & $(0.007)$ & $(0.007)$ \\
\hline \multirow{2}{*}{ Employment status } & 0.005 & $-0.028^{* * *}$ & -0.023 & $-0.017^{* *}$ \\
\hline & $(0.008)$ & $(0.009)$ & $(0.016)$ & $(0.016)$ \\
\hline \multirow{2}{*}{ Service project publicity } & $0.040^{* * *}$ & $0.039^{* * *}$ & $0.041^{* * *}$ & $0.046^{* * *}$ \\
\hline & $(0.007)$ & $(0.008)$ & $(0.013)$ & $(0.013)$ \\
\hline \multirow{2}{*}{ Health record } & $0.017^{* *}$ & $0.030^{* * *}$ & $0.039^{* *}$ & $0.030^{* * *}$ \\
\hline & $(0.008)$ & $(0.009)$ & $(0.016)$ & $(0.016)$ \\
\hline \multirow{2}{*}{ Social security card } & 0.007 & $0.019^{* *}$ & $0.029 * *$ & $0.015^{* * *}$ \\
\hline & $(0.007)$ & $(0.008)$ & $(0.013)$ & $(0.013)$ \\
\hline \multirow{2}{*}{ Basic medical insurance } & $0.017^{* *}$ & 0.014 & 0.014 & $0.022^{* * *}$ \\
\hline & $(0.007)$ & $(0.009)$ & $(0.015)$ & $(0.015)$ \\
\hline Province level fixed effects & Yes & Yes & Yes & Yes \\
\hline Observations & 23,506 & 20,266 & 6815 & 35,119 \\
\hline
\end{tabular}

Note: ${ }^{*}, * * * *$ denote statistically significant difference at the $1 \%, 5 \%$ and $10 \%$ significance level.

Not all health education methods were positively correlated to healthcare-seeking behavior (Table 5). Among the four different tracer disease samples, the results were highly similar. Lectures, public consultation, and online education were significantly positively correlated with migrant workers' behavior in seeking healthcare after illness. For example, in the sample with diarrhea, migrant workers who received lectures, public consultation, and online education were $3.1 \%, 3.0 \%$, and $2.9 \%$ more likely to seek healthcare, respectively. However, the healthcare-seeking behavior of these four tracer diseases was not significantly related to publicity materials and bulletin boards. Different health education methods showed consistent significance in the four models, which showed that the results were robust. 
Table 5. Effect of different health education methods on healthcare-seeking behavior (Probit).

\begin{tabular}{ccccc}
\hline Variable & Diarrhea & Fever & Skin Rash & Common Cold \\
\hline Knowledge lecture & $0.031^{* * *}$ & $0.018^{*}$ & $0.039^{* *}$ & $0.021^{* * *}$ \\
& $(0.008)$ & $(0.010)$ & $(0.016)$ & $(0.007)$ \\
Publicity material & 0.002 & -0.003 & 0.029 & -0.007 \\
& $(0.011)$ & $(0.012)$ & $(0.020)$ & $(0.009)$ \\
Bulletin board & 0.010 & 0.004 & -0.021 & 0.003 \\
& $(0.009)$ & $(0.010)$ & $(0.018)$ & $(0.008)$ \\
Public consultation & $0.030^{* * *}$ & $0.034^{* * *}$ & $0.056^{* * *}$ & $0.033^{* * *}$ \\
Online education & $(0.009)$ & $(0.010)$ & $(0.017)$ & $(0.007)$ \\
Control variables & $0.029^{* * *}$ & $0.016^{*}$ & $0.043^{* * *}$ & $0.023^{* * *}$ \\
Province level fixed effects & $(0.008)$ & $(0.009)$ & $(0.016)$ & $(0.007)$ \\
Observations & Yes & Yes & Yes & Yes \\
\hline
\end{tabular}

Note: ${ }^{*}, * *, * * *$ denote statistically significant difference at the $1 \%, 5 \%$ and $10 \%$ significance level.

\section{Discussion}

We found that the proportion of migrant workers in China who chose healthcare-seeking behavior after illness was relatively low. After experiencing diarrhea, fever, skin rash and common cold, the proportions of migrant workers who chose to seek healthcare were $29.3 \%, 51.6 \%, 55.2 \%$, and $39.4 \%$, respectively, far lower than the national average [32]. This conclusion supported the view that health advantages of migrant workers might gradually weaken after they arrive in cities with better medical conditions [33]. In the case of unknown etiology, if migrant workers do not choose medical treatment in time, their health may be seriously affected. Especially for fever, cold, and other infectious diseases, not seeking medical treatment may harm other people.

We also analyzed the reasons why migrant workers did not choose healthcare-seeking behavior. "I have heard of it before, I think I have treatment experience" and "I am too busy to seek healthcare" were the main reasons why most of the migrant workers chose not to seek healthcare after being ill. To some extent, these two reasons showed that the patients overestimated their physical ability and ignored their conditions. It is undeniable that experience-based coping can probably obtain the right medicine, and some diseases can also achieve self-healing by the autoimmune system. However, the causes of illness may be various. The wrong judgment may lead to severe consequences such as the aggravation of conditions, which need to be avoided. In addition, "I am too busy to seek healthcare" may also be due to the low labor contract signing rate of migrant workers. According to the survey of the Chinese government, only $35.1 \%$ of migrant workers signed labor contracts in 2016 [34], but in the same year, the labor contract signing rate of Chinese enterprises reached more than $90 \%$ [35]. Without the guarantee of labor contracts, migrant workers' work status is precarious and vulnerable. Some migrant workers even get paid by the day, which means that leaving work to seek healthcare will cause wage losses. Future policies need to improve the signing rate of migrant workers' labor contracts to ensure stability of employment. Besides, the proportion of migrant workers who think they can recover, have lack of money, or feel that they are being troublesome in seeking medical aid is relatively low. This result showed that the objective restrictions represented by lack of money and lack of medical service availability were not the main reasons to restrict most people's access to health services. This conclusion conflicted with Peng et al. (2010) [9], indicating that the work of the Chinese government in recent years to protect migrant workers' access to health services has been effective.

Due to government subsidies, the coverage of public health services for migrant workers has been dramatically improved [6]. However, the proportion of migrant workers who choose medical treatment was still low. Therefore, to promote the healthcare-seeking behavior of migrant workers, we should consider not only the supply side of public health services but also the demand side [36]. 
Society should guide migrant workers to form scientific medical habits. Overall planning of health service supply and demand is crucial to change the underutilization of health services of migrant workers in China. Our results showed that some migrant workers overestimated their abilities and neglected their conditions. To solve this problem, we should carry out effective health education, letting migrant workers understand the diversity of causes and the severity of the disease, to raise their attention and finally improve their medical behavior.

Based on these statistics, we further empirically explored the relationship between health education and healthcare-seeking behavior of migrant workers in China. Our results showed that health education could significantly promote the healthcare-seeking behavior of migrant workers. The regression results were consistent with the existing literature that health education was firmly related to healthcare-seeking behavior [24], indicating that China's policy has had some achievements in the implementation of health education for migrant workers. The popularization of health education is an effective way to improve migrant workers' healthcare-seeking behavior. However, considering the four tracer diseases, the probability that health education could improve migrant workers' healthcare-seeking behavior was less than $4 \%$, indicating that there was ample space for improving health education. Meanwhile, the proportion of migrant workers who had received health education was less than $70 \%$. The popularity of health education still needs to be improved.

We also found that not all health education methods were positively correlated to healthcare-seeking behavior. Lectures, public consultation, and online education were the health education methods that positively associated with healthcare-seeking behavior. At the same time, publicity material and bulletin boards were not significantly correlated to healthcare-seeking behavior. This result showed that migrant workers were more inclined to face-to-face learning like lectures and public consultation when they received health education. The health education methods of publicity materials and bulletin boards tended to let migrant workers learn by themselves. This traditional way of education might be annoying, making it difficult to stimulate an interest of learning $[37,38]$. Online education also requires self-study but played a significant role in improving the healthcare-seeking behavior of migrant workers. The reason for this phenomenon may be that online education had sufficient information and more convenient access to information. With the increasing popularity of the Internet, online education with lower cost and more diverse forms will be an essential approach to health education in the future.

It was worth noting that publicity material and bulletin boards, which had no significant impact on the medical behavior of migrant workers, were still the two most commonly used health education approaches of the government. Publicity material and bulletin board accounted for $83.8 \%$ and $72.7 \%$ of the migrant workers who had received health education, respectively. Lectures, public consultation, and online education, which had significant impacts on migrant workers, only accounted for about $40 \%$. This condition partly explains the results that health education had significant but insufficient effects on healthcare-seeking behavior. The possible reason was that for government clerks, traditional education approaches, such as publicity materials and bulletin boards, were the most commonly used methods and the least costly. Lectures and public consultation had higher requirements for human, material, and financial investment, leading to their low availability. As a new method of health education, online education has no ready-made working standard. It needs grass-roots workers to explore and develop by themselves, and the corresponding learning cost is high. Rationally, when the educational effect is not included in the work assessment, these most commonly used method of health education is the best choice for the government clerks.

There are several limitations to our study. First, we chose migrant workers' healthcare-seeking behaviors as dependent variables to test the effects of health education. The direct effect of health education should be health knowledge [39,40], to improve the medical behavior of migrant workers. The mediating effect of health knowledge between health education and healthcare-seeking behavior may be tested in future research. Second, when measuring healthcare-seeking behavior, we only chose to seek healthcare after illness. However, other indicators of healthcare-seeking behavior, such as 
where to seek healthcare, were not included in the analysis. Future research can select more variables to measure the concept of healthcare-seeking behavior according to different aspects of patients' medical treatment. Third, we only chose the method of receiving health education as the independent variables, without distinguishing possible differences in the quality of education. Future research can test the effect and quality of the education method, providing more detailed suggestions for optimizing health education method.

\section{Conclusions}

This paper studied the healthcare-seeking behavior of migrant workers regarding four diseases, namely diarrhea, fever, skin rash, and common cold. To some extent, the objective limitation (e.g., lack of money or medical service availability) of healthcare-seeking behavior faced by migrant workers has been alleviated. However, due to subjective reasons (e.g., the overestimation of physical ability and neglect of disease) caused by lack of education knowledge, the proportion of migrant workers who chose to go to seek healthcare after disease was still low. Health education could significantly improve the healthcare-seeking behavior of migrant workers, but there is still ample space for improvement. Not all health education methods were significantly correlated to healthcare-seeking behavior. Lectures, public consultation, and online education were positively related to healthcare-seeking behavior, while publicity material and bulletin boards were not. More significantly, although the effects of publicity materials and bulletins were limited, these two health education methods are still the two most widely used methods. Therefore, investment in lectures, public consultation, and online education remains to be strengthened. Increasing investment in these three methods, especially improving the standardized implementation mode of online education, is of significance to promote the development of health education. This study provides evidence for understanding the health education of migrant workers and promotes the development of health education. At the same time, with the worldwide outbreak of COVID-19, people in some countries still do not pay enough attention to health, bringing challenges. We hope that this paper can give some inspiration to governments in other countries to improve people's attention to health through effective health education.

Author Contributions: All authors contributed extensively to the work presented in this paper. Data curation, X.L. (Xujun Liu); Methodology, X.L. (Xuefeng Li) and H.Y.; Project administration, H.W.; Supervision, X.L. (Xuefeng Li); Writing-original draft, X.L. (Xuefeng Li); Writing—review \& editing, H.Y. and H.W. All authors have read and agreed to the published version of the manuscript.

Funding: This study was funded by Fundamental Research Funds for the Central Universities (JBK2001047).

Acknowledgments: The authors would like to thank the technical and financial support of Fundamental Research Funds for the Central Universities. The authors also gratefully acknowledge the support of editors and anonymous reviewers for reviewing this research and providing very helpful suggestions for improvement.

Conflicts of Interest: The authors declare no conflict of interest.

\section{References}

1. Hargreaves, S.; Rustage, K.; Nellums, L.B.; Mcalpine, A.; Pocock, N.; Devakumar, D.; Aldridge, R.W.; Abubakar, I.; Kristensen, K.L.; Himmels, J.W.; et al. Occupational health outcomes among international migrant workers: A systematic review and meta-analysis. Lancet Glob. Health 2019, 7, E872-E882. [CrossRef]

2. National Bureau of Statistics of China. 2018 Migrant Workers Monitoring Survey Report. Available online: http://www.stats.gov.cn/tjsj/zxfb/201904/t20190429_1662268.html (accessed on 29 April 2019).

3. Liu, Z.Q. Institution and inequality: The hukou system in China. J. Comparat. Econ. 2005, 33, $133-157$. [CrossRef]

4. Wong, D.F.K.; Li, C.Y.; Song, H.X. Rural migrant workers in urban China: Living a marginalised life. Int. J. Soc. Welf. 2006, 16, 32-40. [CrossRef]

5. Afridi, F.; Li, S.X.; Ren, Y. Social identity and inequality: The impact of Chinas hukou system. J. Public Econ. 2015, 123, 17-29. [CrossRef] 
6. Zhang, J.; Lin, S.; Liang, D.; Qian, Y.; Zhang, D.; Hou, Z. Public health services utilization and its determinants among internal migrants in China: Evidence from a nationally representative survey. Int. J. Environ. Res. Public Health 2017, 14, 1002. [CrossRef] [PubMed]

7. Liang, Y.; Guo, M. Utilization of health services and health-related quality of life research of rural-to-urban migrants in China: A cross-sectional analysis. Soc. Indicat. Res. 2014, 120, 277-295. [CrossRef]

8. State Council Research Office Discussion Group. Research Report on Migrant Workers in China; China Yanshi Publishing House: Beijing, China, 2006; pp. 236-247.

9. Peng, Y.; Chang, W.; Zhou, H.; Hu, H.; Liang, W. Factors associated with health-seeking behavior among migrant workers in Beijing, China. BMC Health Ser. Res. 2010, 10. [CrossRef]

10. Hao, A.H.; Zhang, W.; Liu, Z.F.; Xu, M.J.; Xu, N.; Liu, L.P.; Deng, H.H. Analysis of basic public health services utilization and influence factors of the floating population in the Pearl River Delta. Chinese J. Public Health Manag. 2016, 32, 613-617. (in Chinese).

11. Hu, X.; Cook, S.; Salazar, M.A. Internal migration and health in China. The Lancet 2008, 372, $1717-1719$. [CrossRef]

12. Batterham, R.W.; Hawkins, M.; Collins, P.A.; Buchbinder, R.; Osborne, R.H. Health literacy: Applying current concepts to improve health services and reduce health inequalities. Public Health 2016, 132, 3-12. [CrossRef]

13. Sentell, T. Implications for reform: Survey of California adults suggests low health literacy predicts likelihood of being uninsured. Health Affair. 2012, 31, 1039-1048. [CrossRef] [PubMed]

14. Franzen, J.; Mantwill, S.; Rapold, R.; Schulz, P.J. The relationship between functional health literacy and the use of the health system by diabetics in Switzerland. Eur. J. Public Health 2014, 24, 997-1003. [CrossRef] [PubMed]

15. Mantwill, S.; Schulz, P.J. Low health literacy and healthcare utilization among immigrants and non-immigrants in Switzerland. Patient Educ. Couns. 2017, 100, 2020-2027. [CrossRef] [PubMed]

16. Haun, J.N.; Patel, N.R.; French, D.D.; Campbell, R.R.; Bradham, D.D.; Lapcevic, W.A. Association between health literacy and medical care costs in an integrated healthcare system: A regional population-based study. BMC Health Ser. Res. 2015, 15, 249. [CrossRef] [PubMed]

17. Paasche-Orlow, M.K.; Wolf, M.S. The causal pathways linking health literacy to health outcomes. Am. J. Health Behavior. 2007, 31, 19-26. [CrossRef]

18. Wei, X.; Pearson, S.; Zhang, Z.; Qin, J.; Gerein, N.; Walley, J. Comparing knowledge and use of health services of migrants from rural and urban areas in Kunming City, China. J. Biosoc. Sci. 2010, 42, 743-756. [CrossRef]

19. Biao, X. SARS and migrant workers in China: An institutional analysis. Asian Pac. Migrat. J. 2003, 12, 467-499. [CrossRef]

20. Nutbeam, D. Health literacy as a public health goal: A challenge for contemporary health education and communication strategies into the 21st century. Health Promot. Int. 2000, 15, 259-267. [CrossRef]

21. Cianfrocca, C.; Caponnetto, V.; Donati, D.; Lancia, L.; Tartaglini, D.; Stasio, E.D. The effects of a multidisciplinary education course on the burden, health literacy and needs of family caregivers. Appl. Nurs. Res. 2018, 44, 100-106. [CrossRef]

22. Saunders, C.; Palesy, D.; Lewis, J. Systematic review and conceptual framework for health literacy training in health professions education. Health Prof. Educ. 2019, 5, 13-29. [CrossRef]

23. Cruden, G.; Kelleher, K.; Kellam, S.; Brown, C.H. Increasing the delivery of preventive health services in public education. Am. J. Prev. Med. 2016, 51. [CrossRef] [PubMed]

24. Barman, B.; Saha, J.; Chouhan, P. Impact of education on the utilization of maternal health care services: An investigation from National Family Health Survey (2015-16) in India. Child. Youth Ser. Rev. 2020, 108, 104642. [CrossRef]

25. Utami, S.; Purwani, W. Increasing mothers' knowledge of cervical cancer risk through peer group health education with "PinKa" method. Enfermería Clínica 2019, 29, 52-55. [CrossRef]

26. Gaughan, M.; Brinckman, D. Telephonic health coaching: An innovative method to promote health behavior change among participants in Supplemental Nutrition Assistance Program-Education (SNAP-Ed). J. Acad. Nutr. Diet. 2016, 116. [CrossRef]

27. Wei, B.; Lu, L.; Zhang, Z.Y.; Ma, Z.Y. Bridging the gap between education and practice in public health, with particular reference to less-developed provinces in China. Public Health 2011, 125, 25-29. [CrossRef] [PubMed] 
28. Zhang, D.; Mou, J.; Cheng, J.Q.; Griffiths, S.M. Public health services in Shenzhen: A case study. Public Health 2011, 125, 15-19. [CrossRef]

29. Griffiths, S.M.; Tang, J.L. Healthcare reform in China and the challenges for public health education. Public Health 2011, 125, 3-5. [CrossRef]

30. Kasl, S.V.; Cobb, S. Some psychological factors associated with illness behavior and selected illnesses. J. Chron. Dis. 1964, 17, 325-345. [CrossRef]

31. Calvin, J.A. Regression Models for Categorical and Limited Dependent Variables. Technometrics 1998, 40, 80-81. [CrossRef]

32. Zheng, L. Has health insurance system changed health care seeking behavior? evidence from Chinese CHNS. Public Fina. Res. 2017, 2, 84-97. (in Chinese).

33. Chen, J. Internal migration and health: Re-examining the healthy migrant phenomenon in China. Soc. Sci. Med. 2011, 72, 1294-1301. [CrossRef] [PubMed]

34. National Bureau of Statistics of China. 2016 Migrant Workers Monitoring Survey Report. Available online: http://www.stats.gov.cn/tjjj/zxfb/201704/t20170428_1489334.html (accessed on 28 April 2017).

35. Ministry of Human Resources and Social Security of People's Republic of China. 2016 Statistical Bulletin on the Development of Human Resources and Social Security. Available online: http://www.mohrss.gov.cn/ SYrlzyhshbzb/zwgk/szrs/tjgb/201805/t20180521_294286.html (accessed on 21 May 2018).

36. Rocha, F.; Duarte, J.; Oliveira, P.P.D.; Pereira, L.F.V.N.; Gadelha, S.R.D.B. Are more resources always the answer? A supply and demand analysis for public health services in Brazilian municipalities. Economi A. 2017, 18, 98-116. [CrossRef]

37. Vlassi, M.; Karaliota, A. The Comparison between Guided Inquiry and Traditional Teaching Method. A Case Study for the Teaching of the Structure of Matter to 8th Grade Greek Students. Procedia-Soc. Behavior. Sci. 2013, 93, 494-497. [CrossRef]

38. Olokundun, M.; Moses, C.L.; Iyiola, O.; Ibidunni, S.; Ogbari, M.; Peter, F.; Borishade, T. The effect of non traditional teaching methods in entrepreneurship education on students entrepreneurial interest and business startups: A data article. Data Brief 2018, 19, 16-20. [CrossRef] [PubMed]

39. Shabaan, H.T.E.A.; Sayed, Y.A.E.; Ghonemy, G. Effect of health teaching on post partum minor discomfort. Beni-Suef Univ. J. Basic Appl. Sci. 2018, 7, 198-203. [CrossRef]

40. Nannyonga, B.K.; Singull, M. Impact of health education on knowledge and behaviours toward obstetric fistula among women of reproductive age in Uganda. Appl. Math. Comput. 2020, 372, 124997. [CrossRef] 